\title{
COMMENTARIES
}

\section{Confidentiality vs harm to another}

\section{SUNIL K PANDYA}

Dr. Bawaskar's sensitivity in this matter deserves applause (1).

The principle of confidentiality dictates that what is discussed by doctor and patient remains between them and should not be divulged to anyone else without the patient's express consent.

A major exception to this diktat is harm to another if confidentiality is maintained. In the US case that is now referred to world-wide when this issue is being discussed, Vitaly Tarasoff et al, Plaintiffs and Appellants, vs Regents of the University of California et al, Defendants and Respondents (2), the judge's decision on July 1,1976 was clear.

Prosenjit Poddar, a student from Bengal, had confided to Dr. Moore, his psychologist, his intent to kill Tatiana Tarasoff for having jilted him. The head of the department of Psychology overruled Dr. Moore's suggestion that Poddar be committed to a psychiatry clinic. Poddar killed Tatiana. In the ensuing trial, the

Author:Sunil K Pandya (shunil3@gmail.com),Department of Neurosurgery

Jaslok Hospital and Research Centre, Dr GV Deshmukh Marg, Mumbai 400 026, INDIA

To cite: Pandya SK. Confidentiality vs harm to another. Indian J Med Ethics. 2019 Jul-Sep;4(3) NS:211.DOI:10.20529/JME.209.036

Published online on July 9, 2019.

( ) Indian Journal of Medical Ethics 2019
California Supreme Court found that a medical professional has a duty not only to a patient, but also to individuals who are in danger consequent to the acts of that patient.

In the case of Dr. Bawaskar's patient, there was a manifest, malignant brain tumour, known to carry a very high risk of mortality.

It is the duty of the treating neurosurgeon to convey this sad news to the patient and his family. Since the patient was of marriageable age, it is obvious that with such a tumour, the union would lead to incalculable harm to the prospective bride. The woman and her parents should have been provided details of the illness and prognosis by the patient and his family. An instruction to this effect from the doctor to his patient would have been correct and salutary.

As matters stand, the doctor failed in his duty as physician, friend, philosopher and guide to his patient, his family and to the hapless, now pregnant, wife.

\section{References}

1. Bawaskar HS. Can doctors advise beyond the purely professional? Indian J Med Ethics. Published online on July 1, 2019. DOI:10.20529/ IJME.2019.035.

2. Supreme Court of California. Vitaly Tarasoff et al, Plaintiffs and Appellants, $v$ Regents of the University of California et al, Defendants and Respondents. 551 P.2d 334 (Cal. 1976). 1976 Jul 1 [cited 2019 Jun 20]. Available from: https://www.courtlistener.com/c/Cal.\%203d/17/425/

\section{The uninformed spouse: Balancing confidentiality and other professional obligations}

\section{SUPRIYA SUBRAMANI}

\section{Abstract}

I use the case study presented by Bawaskar (1), which I refer to as

Author: Supriya Subramani (supriyasubramani90@gmail.com), Researcher Bioethics and Medical Law, and Associate, Health, Ethics and Law Institute for Training, Research and Advocacy, Nav Bhavna CHSL, 422, Veer Savarkar Marg, Prabhadevi Mumbai 400025 INDIA.

To cite: Subramani S. The uninformed spouse: Balancing confidentiality and other professional obligations. Indian J Med Ethics. 2019 Jul-Sep;4(3): NS:21115. DOI: 10.20529/IJME.2019.046.

Peer reviewer:Veena Johari

(๑) Indian Journal of Medical Ethics 2019 the "The Case of the Uninformed Spouse", to illustrate an ethical conflict between medical confidentiality and the duty to protect and inform an involved third party, who in this case is the patient's spouse. The central question raised by Bawaskar based on this case is, "Is it the physician's professional obligation to counsel the patient against marriage?" In this commentary, I will attempt to answer this question while also engaging with the ethical conflict in this case and what issues may arise if the physician had indeed considered revealing information to the patient's partner against the wishes of the patient. I engage on the concept of "harm" to discuss the moral scope of the duty to warn an involved third party and when it is justified to breach confidentiality of the 